\title{
TRADUCIR COMO PRÁCTICA CULTURAL. TERTULIAS, ACADEMIAS Y TRADUCCIÓN EN LA ESPAÑA DEL SIGLO XVIII
}

\begin{abstract}
ANDREAS GELZ
1. Frente a lo comúnmente pensado, traducir no es en absoluto una actividad solitaria; puede más bien resultar - como intentaremos probar al hilo de algunas tertulias y proyectos académicos del siglo XVIII- una actividad colectiva, y desempeñar a la vez un papel importante en el proceso de formación de una nación ${ }^{1}$. El hecho de que movilice representaciones de asimetría intercultural (mayoritariamente entre España y los países septentrionales, representantes de la Ilustración; sobre todo Francia), convierte a la traducción en una práctica sociopolítica y cultural ambivalente que, precisamente en virtud de su carácter transfronterizo, implica la problemática del límite y, por lo tanto, de la constitución de la comunidad conforme a las características esenciales de la cultura española. Es en este sentido que la traducción está relacionada con procesos intersubjetivos o sociales, en tanto que pone en movimiento imágenes tradicionales de sí mismo y de lo ajeno. Por traducción en ese contexto se entiende la traducción en sus sentidos intra e interlingüístico; asimismo se puede hablar de traducción cultural.

Las siguientes aportaciones parten de la hipótesis según la cual la traducción como acto comunicativo nunca saldrá de su aporía: la heterogenei-

1 Cfr. al respecto la tipología de la traducción que propone Inmaculada Urzaínqui tras analizar cerca de 100 prólogos a traducciones del s. XVIII. Entre otras, se describe la que ella llama «traducción-nacionalización» (vid. URZAÍNQUI, J., «Hacia una tipología de la traducción en el siglo XVIII: los horizontes del traductor», en DONAIRE, M. L., LAFARGA, F. (eds.), Traducción y adaptación cultural: España-Francia, Universidad de Oviedo, 1991, pp. 623-63). También otras de las así llamadas categorías, como la «traducción-restitución», para la que trae a colación la traducción del Padre de Isla con el significativo subtítulo de «robadas a España y adoptadas en Francia por M. Le Sage, restituidas a su patria y a su lengua nativa por un español celoso, que no sufre se burlen de su nación» (ibíd., p. 625), podrían encuadrarse en la primera de las categorías mencionadas. Cfr. asimismo ÁlvAREZ BARRIENTOS, J., «Traducción y novela en la España del siglo XVIII. Una aproximación», en GARCÍA LARA, F. (ed.), I Congreso Internacional sobre Novela del siglo XVIII, Universidad de Almería, 1998, pp. 9-22, en especial «Traducción y nacionalismo» (pp. 12-15).
\end{abstract}


dad de lenguas y moldes discursivos jamás podrá superarse por completo. Es ésta una de las razones por las que la traducción parece necesariamente sospechosa en una sociedad feudal, obediente al discurso religioso, garante del horizonte semántico de la comunidad que se transmite a través de una jerarquía sin fisuras, y que todavía no ha realizado el cambio de un sistema denotativo unívoco y transparente a una concepción lingüística histórica y basada en la arbitrariedad de los signos. Esa hipótesis parece todavía más justificada en una época de cambios culturales, de problemática con las autoridades existentes o con las estructuras discursivas tradicionales, de ambigüedad cada vez mayor en el saber cultural de la sociedad, de un proceso, en suma, de secularización. En una situación tal como la que acabamos de describir, se hace preciso, en el sentido amplio de la palabra, un trabajo de traducción intra e interlingüística; esto es, un desafío a la heterogeneidad de un saber que se manifiesta en una multiplicidad de sistemas discursivos y conceptuales: su negociación entre diferentes grupos sociales con normas y valores diferentes, la búsqueda de un lenguaje común, de una autoridad (lingüística y literaria; textual) que lo legitime. Resulta obvio, después de lo dicho, que la traducción aparezca en esa situación de transición cultural como un paradigma general para probar la capacidad comunicativa y de autoreflexión de una sociedad en cambio.

Esta hipótesis se verificará en lo que sigue; se evitará el relato de un catálogo de estereotipos culturales que se hubieran coleccionado bajo una perspectiva imagológica, así como una lectura de prólogos más o menos programáticos a algunas traducciones, escritos por los propios traductores; tampoco ocuparán el centro de nuestra atención los tipos de enajenamiento cultural —en la mayoría de los casos, de afrancesamiento-, o estadîsticas que nos informaran de cuáles serían los textos traducidos y cuál su procedencia, y, en consecuencia, sobre el tipo de saber traducido e introducido en España. Más bien se trata aquí de considerar la práctica concreta de la traducción, sus vertientes cultural y social, su integración y utilización en procesos de comunicación social, siempre en el contexto del nacimiento de una identidad nacional.

Si hablamos, pues, de traducción, nuestra mirada se dirige por supuesto hacia los literatos como grupo social, del que proceden, en su mayor parte, los traductores. Para este grupo cuyo oficio, según su propia opinión, es la realización (estética) de procesos comunicativos en un marco nacional, la actividad de malos traductores, responsables, siempre según la misma opinión, de la enajenación y la decadencia de la sociedad española del siglo XVIII, constituye un importante reparo en cuanto a la imagen pública de los miembros de la República de las Letras in statu nascendi. La exigencia, a menudo fomentada por los literatos, de una profesionalización de la actividad literaria y, en consecuencia, de una mejora del nivel de la traducción, tiene por objeto último la consolidación y autonomía 
de la República de las Letras; sin embargo, pudo ser presentada asimismo como la contribución de los literatos al proceso de formación de una identidad nacional en el contexto europeo. Las reflexiones que vamos a presentar en lo siguiente intentan contribuir, con su doble enfoque sobre la traducción y su papel en y para las formas de sociabilidad o sociedad en el siglo XVIII español, a la problemática de la formación y de la significación de la República Literaria de la segunda mitad del siglo ${ }^{2}$.

Es por ello que este artículo atiende en primer lugar a los ejemplos de sociabilidad informal - las tertulias ${ }^{3}$-, así como a dos proyectos de fundación de una academia científica a finales del siglo XVIII, proyectos que consoliden los tópicos surgidos en las discusiones de las diferentes tertulias. Las traducciones a las que dedicaremos especial atención provocan en sus diferentes ámbitos un cambio en virtud de una revalorización intercultural: Feijoo y sus adaptaciones del francés con miras a la Ilustración europea y su recepción crítica en España; Gracián y su traducción al italiano con vistas a una reorientación poética hacia un neoclacisismo.

2. El análisis de la relación entre tertulia y traducción en el horizonte de las preguntas que acabamos de esbozar, puede interesar por más de una razón: La tertulia se puede considerar como un lugar de confrontación y cambio de discursos heterogéneos e influencias interculturales, de mediación para un encuentro cultural que no sólo se refiere a la cultura extraña - y por lo tanto a la traducción-, sino también a la propia situación epistemológica de la sociedad española del siglo XVIII, caracterizada por una gran asincronía y por un desfase en la producción y recepción del saber en los diferentes sectores de la sociedad, y confrontada así con la necesidad de una traduccion cultural, intralingüística ${ }^{4}$.

Estas propiedades de la tertulia están sujetas a una dura crítica en la sociedad de la segunda mitad del siglo XVIII ${ }^{5}$; incluso se puede sostener

2 Para este asunto véase la obra de Álvarez BARRIEnTos, J., et al., La República de las Letras en la España del siglo XVIII, Madrid, CSIC, 1995, p. 9.

3 Las siguientes reflexiones forman parte de un proyecto de investigación financiado por la Deutsche Forschungsgemeinschaft sobre el papel de la tertulia en la España de los siglos XVIII y XIX. Véase al respecto GELZ, A., «La tertulia - sociabilidad, comunicación y literatura en el siglo XVIII: perspectivas teóricas y ejemplos literarios (Quijano, Jovellanos, Cadalso)», en Cuadernos de estudios sobre el siglo XVIII español (en prensa).

4 Cfr. en el mismo contexto el significado de la tertulia en los diarios de viaje o en la literatura ilustrada en que se observa la autocrítica nacional desde la perspectiva de un extranjero; por ejemplo, en las Cartas Marruecas de José Cadalso.

5 Apenas si hay textos del siglo XVIII que no se correspondan con las numerosas tertulias afrancesadas de la burguesía naciente; apenas un texto que no fije su mirada en los galicismos, los petimetres, las damas de nuevo cuño, los abates y demás especímenes del género. Del mismo modo, esta crítica va con frecuencia acompañada 
que esta crítica articulada dentro y fuera de la tertulia ha llevado, quizá por vez primera, a la imbricación e implicación de los diferentes sectores de la sociedad y, de esta manera, a un proceso conflictivo de constitución de una esfera pública. La tertulia, por su carácter informal y su constitución a veces heterogénea, aparece además como un proceso dinámico de transacción social, como una anticipación de una nueva, siempre maleable estructura social, como metonímia de un espacio políticamente representativo en el que las normas y los valores comunicativos que se ponen a prueba abarcan siempre el núcleo de una generalizacion al conjunto de la sociedad $^{6}$. Y no en último lugar a causa de la amplitud de la noción: tertulia significa a la vez el lugar de los procesos comunicativos, el conjunto de los participantes así como la comunicación misma.

La tertulia es tanto el lugar de gestación de una República Literaria en vía de formación, como el de su encuentro con la sociedad, el público, con la opinion pública, cuya constitución favorece al permitir y realizar procesos autoreflexivos entre sus miembros. Para limitarnos al ejemplo de la traducción, cabe decir que es de la tertulia de donde salen los traductores; ella representa el público en cuyo desarrollo influye la traducción, y es el lugar en que se discuten las modalidades de ésta y se valoran sus resultados.

de la advertencia sobre malos traductores, que introducen galicismos en España y contribuyen así a la alienación de la lengua y la cultura españolas. Véase, por ejemplo, RuBIo, A., La crítica del galicismo en España. 1726-1832, México, Ediciones Universidad Nacional, 1937; CHECA BELTRÁN, J., «Opiniones dieciochistas sobre la traducción como elemento enriquecedor o deformador de la propia lengua», en DONAIRE/LAFARGA, op. cit., pp. 593-602.

6 Esto resulta especialmente significativo cuando se contempla la tertulia no como fenómeno aislado, sino como parte de una red tejida por los miembros de más de una tertulia. Contémplese en este contexto la reserva de la Autoridad estatal con la tertulia no institucionalizada y por ello más difícil de controlar. Así se prohíbe en un bando real con fecha del 18 de abril de 1766 «la composicion de Pasquines, Sátiras, Versos, Manifiestos, y otros Papeles sediciosos [...] algunas Personas ociosas, y de perniciosas intenciones componen, distribuyen, y expenden estos Papeles sediciosos, que incautamente se leen en tertulias y conversaciones, sin conocer el artificio de sus composiciones: $\mathrm{Y}$ deseando el Consejo apartar esta zizaña de la República [...] manda se haga saber por Edicto á todos los Vecinos estantes, y residentes en esta Corte de qualquier estado, calidad, y condicion que sean, se abstengan de componer, escribir, trasladar, distribuir, ni expender semejantes Papeles sediciosos, é injuriosos, ni de permitir su lectura». Resulta interesante resaltar que este bando, al no distinguir entre autores y receptores concretos, entre los géneros de los textos condenados, cree por vez primera una opinión pública nacional, siendo una de sus cualidades una estrecha interdependencia de literatura (traducción) y sociedad; en este sentido es paradójico, ya que la orden real pretendía impedir el nacimiento de dicha opinión pública. De todo ello se desprende el importante papel que desempeñan las tertulias en dicho contexto. Véase GELZ, A., "Les Lumières du scandale: le motín de Esquilache (1766) - conflit culturel et expérience d'altérité au XVIIIe siècle espagnol», en BELL, D. A., PImenova, L., Pujol, S. (eds.), Raison universelle et culture nationale au XVIII ${ }^{e}$ siècle, París, Champion, 1999, pp. 149-178. 
La relación entre tertulia y traducción se puede describir de distintas maneras; se pueden analizar textos o traducciones en cuya elaboración la tertulia tuvo un papel protagonista ${ }^{7}$, o analizar representaciones literarias de tertulias, donde de uno u otro modo la traducción ocupe un primer plano (vid. 4).

Nuestras anotaciones a la traducción de la primera égloga de Garcilaso de la Vega en italiano, realizada por Juan Bautista Conti, es un ejemplo del primer tipo mencionado. Este texto aparece en la edición de Casimiro Gomez Ortega en el año 1771; Gomez Ortega es al mismo tiempo autor de un prólogo a la traducción ${ }^{8}$. Traductor y editor son miembros de la tertulia de la Fonda de San Sebastián, que se puede considerar como el marco de una relación cultural italo-española, y a la vez de la renovación poética de España bajo el signo de un neoclasicismo italianizante ${ }^{9}$. La traducción de un poema de Garcilaso es la expresión programática de esa política cultural neoclásica ${ }^{10}$. El interés de este grupo en cuestiones de poética, de

7 A título de ejemplo remitamos a un análisis de la traducción del teatro francés del s. XVII en la tertulia de Pablo de Olavide en Sevilla. Cfr. una lista de las piezas traducidas en TOliVAR AlAS, A. C., "Phèdre de Racine en la España del siglo XVIII», en DonAIRE/LAFARGA, op. cit., pp. 433-442, en especial las pp. 438-441; también Defournaux, M., Pablo de Olavide ou l' afrancesado (1725-1803), París, PUF, 1959, pp. $75-80$.

8 Cfr. La célebre écloga primera de Garcilaso de la Vega. Con su Traduccion Italiana en el mismo metro. Por el Conde D. Juan Bautista Conti. La da á Luz Con él Prólogo, Resumen de la Vida del Poeta, y algunas observaciones el Dr. D. Casimiro Gomez Ortega. Madrid, Joachin Ibarra, 1771 (Bibl. Menéndez Pelayo, Santander 2.333).

9 La tertulia de la Fonda de San Sebastián es frecuentada por el editor Casimiro Gomez Ortega, boticario y futuro catedrático de botánica; Conti, su amigo Moratín, que le ha llamado la atención sobre el poema de Garcilaso; Napoli-Signorelli, traductor al italiano de obras, entre otros, de Moratín; Juan de Iriarte, bibliotecario de la Biblioteca Real y reconocido cosmopolita que vivió en Roma, Londres y París, desde 1742 «Oficial Traductor de la Primera Secretaría de Estado»; Cadalso, que presenta en la tertulia parte de sus Cartas Marruecas; P. Scio, Ignacio López de Ayala, humanista políglota que publicó una tragedia, Numancia destruída, así como una Historia de Federico el Grande de Prusia, y fue el primer catedrático de poética de los Estudios de San Isidro; fue también censor y corrector de comedias, a la vez que miembro de numerosas academias; Mariano Pizzi y Frangheschi, italiano de origen aunque de nacionalidad española, doctor en medicina y «catedrático de lengua arábiga» en los Reales Estudios de San Isidro en Madrid; también formaban parte de la tertulia los eruditos valencianos Francisco Cerdá y Rico, y Juan Bautista Muñoz, bien relacionados con el mundo editorial y editores ambos de textos clásicos españoles (Lope de Vega, Luis de Granada), al haber asimismo ejercido la docencia y destacar, en el caso de Muñoz, con su inacabada Historia del Nuevo Mundo. Sobre la tertulia de la Fonda de San Sebastián, véase la obra de Cotarelo y Mori, E., Iriarte y su época, Madrid, Sucs. de Rivadeneyra, 1897, pp. 111-127.

10 Véase asimismo el aún más extenso proyecto de traducción de Conti, la Colección de poesías castellanas traducidas en verso toscano, é ilustradas por el conde don Juan Bautista Conti. Primera Parte (Madrid, Imprenta Real, 1772 y ss.), con el cual pretendía dar a conocer el florilegio del arte poético castellano. En el primer volumen 
filología, su poliglotismo, su vinculación a los problemas de la traducción es el trasfondo con el cual debe leerse la traducción del poema de Garcilaso. Destacan en esa edición, además de la propia traducción de Conti, algunos textos suplementarios de los miembros de la tertulia y otras personalidades que acompañan o circundan la misma traducción. Junto al prólogo, hallamos mayoritariamente poemas en latín, español o italiano -que, dicho sea de paso, constituyen en sí mismo un contexto intercultural en el que situar la traducción, contexto que de por sí la justificaría-, que nos sugieren, mas allá de los elementos encomiásticos de rigor, algo sobre los procesos y criterios de selección que guiaron la elección de este poema para la traducción: y, al tropezar con comentarios y esbozos de interpretación, o con otros elementos añadidos, también sobre el traductor y su contexto cultural. Estos textos adjuntos pueden considerarse como indicios de la dimension autoreflexiva de esta publicación casi colectiva, dimensión que se refiere al grupo social que se articula en tales textos ${ }^{11}$.

Según esta propuesta de lectura, es al prólogo de Gomez Ortega al que incumbe la tarea de introducir al lector en esta estructura textual que acabamos de describir en analogía con la tertulia como estructura comunicativa. No bien se ha empezado la lectura del prólogo, sorprende, en efecto, cómo Gomez Ortega relaciona la actividad traductora con dos campos aparentemente ajenos a la literatura: el de la hospitalidad entre personas, grupos o naciones, y el del intercambio, el de la circulación de ideas y valores. El prólogo empieza por esbozar la idea del don recíproco: al agradecimiento del trato y de la amistad que había tenido Gomez Ortega con Conti hace años en Padua («desde el tiempo en que logré la fortuna de conocerle, y tratarle»), corresponde su disposición para introducirle a la literatura de su propio país: «Ya desde aquel tiempo procuré, en recompensa del agasajo, y amistad con que me favoreció, satisfacer su loable curiosidad, comuni-

hallamos un repaso histórico al origen y evolución de la poesía en lengua castellana. De nuevo aquí es reconocible la función que tiene la tertulia como lugar de intercambio cultural: las noticias sobre este proyecto proceden de nuevo de los miembros de la tertulia de la Fonda de San Sebastián, así como de otros pertenecientes a otras tertulias en las que Conti participaba junto a Velázquez, Sarmiento, Tomás A. Sánchez y Ortega, entre otros. Los dos siguientes volúmenes aparecieron sólo en italiano y ya fuera de la península (cfr. Cotarelo y Mori, op. cit., p. 114).

11 De gran utilidad para confirmar esta perspectiva resulta la siguiente afirmación de Antonio Alcalá Galiano, con la que describe la en aquellos tiempos práctica literaria al uso. Trata de la polémica entre los partidarios de Moratín y los de Quintana: «Pero el campo de batalla de las opuestas huestes estaba en los apéndices puestos por los traductores o por amigos de los traductores a los originales; apéndices destinados a juzgar, aunque por encima, las obras de nuestra literatura antigua y moderna. Para los moratinistas la primera era en grado sumo preferible; para los quintanistas, la segunda» (AlCalá Galiano, A., Recuerdos de un anciano, en Obras escogidas de Antonio Alcalá Galiano, vol. I, Madrid, Atlas [BAE 83], p. 29). 
cándole alguna idea de nuestras riquezas poéticas, y excitándole vivos deseos de instruirse bien en la Lengua Española» (p. 3). De esta manera el ámbito de la sociabilidad informal («conocerle, y tratarle», «agasajo, y amistad») se conecta de forma muy compleja con la idea de un encuentro intercultural en el que cabe colocar también la transmisión de textos literarios. Refiriéndose a este encuentro (y eso importa al valorar la contribución intercultural concreta de la tertulia de la Fonda de San Sebastián) se habla también de la introducción, de la dirección del extranjero en la propia cultura («comunicándole alguna idea de nuestras riquezas poéticas»).

No sólo hablamos, en el caso del encuentro que nos ocupa, de dos espacios culturales, sino también, como veremos, de dos espacios históricos distintos. La gran importancia que tiene, según Gomez Ortega, la tertulia para el encuentro intercultural, se percibe ya en el hecho de que el relato de la integración progresiva de Conti en la tertulia de la Fonda de San Sebastián y de su encuentro (literario) con Garcilaso es un eco lejano del encuentro que tuvieron otros autores italianos con el propio Garcilaso siglos atrás: "Celebraron el mérito de Garcilaso los propios, y estraños, y señaladamente entre estos últimos Paulo Jovio, el Bembo, y otros Poetas Toscanos, á quienes trató en Nápoles, grangeándose la amistad, y el aplauso de todos los Sabios de Italia» (p. 13), como se dice en el Resumen de la vida de Garcilaso de la Vega que sigue al prólogo. Con esta comparación implícita, Ortega sitúa la tertulia de la Fonda de San Sebastián en una sucesión secular del encuentro intercultural como fundamento de cualquier comunidad - un gesto legitimador de grandes pretensiones políticas y culturales.

Gomez Ortega nos describe, pues, cómo se introduce y se prepara al que será más tarde traductor de Garcilaso en la cultura española y su futuro mediador. Por aquel entonces Conti no había aún aprendido español «por falta de quien le dirigiese á los principios, y tambien por la escasez que allí se padece de las Obras de nuestros mejores Poetas» (p. 3). Sin ese medio, se nos dice, no puede haber conocimiento; pero la cita nos revela también la finalidad de la publicación que estamos analizando: la de contribuir al conocimiento de la cultura española en Italia. «[S]u venida á estos Reynos le ha facilitado posteriormente el conocimiento de la hermosa estructura, magestad, y nobleza de la Lengua Castellana, la noticia de nuestros mejores Poetas, el cotejo de los lenguages poéticos Español, y Toscano, y finalmente la formacion de esta Obra» (p. 4): Esta gradación describe un aprendizaje y un conocimiento progresivo: partiendo del dominio de la lengua y su literatura, se pasa a la comparación de dos lenguas con la mirada puesta en las necesidades de la traducción para poder concretarla después. Al leer estos pasajes percibimos que la traducción de Conti ya no se puede distinguir del afán pedagógico y crítico de la tertulia. Al final del prólogo vuelve a mencionarse la idea del don recíproco, y las palabras 
introductoras de la cita siguiente insisten en el papel de la tertulia como resorte y a la vez marco de la traducción: «Algunos Españoles tambien hemos creido deberle dar al Sr. Conti muchas gracias, de que se haya dedicado á acreditar fuera del Reyno la poesia Española, y á comunicar principalmente á Italia el conocimiento de nuestras riquezas poéticas» (p. 11).

El prólogo intenta pronunciarse sobre la calidad de la traducción a través de un examen del texto original ${ }^{12}$, y el lector es testigo de una elaboración colectiva de un cánon literario dentro y a través de la tertulia. Adaptado al estilo oral, Gomez Ortega introduce un «nosotros» en los pasajes del prólogo que dedica a Garcilaso: «¿Qué dirémos del sumo juicio, y discrecion, que se advierte en la disposicion [?]» (p. 4), un pronombre, que, al margen de lo retórico, puede leerse como indicio de la constitución de una comunidad: la crítica (p. 5). La validez de esa lectura se puede comprobar en otros lugares. Como, por ejemplo, cuando se dice de Garcilaso que escribe «con tal soltura, magisterio, y novedad, que mas bien que imitacion, deberia llamarse creacion propia de nuestro Poeta. En la Estancia XXIV de la segunda Parte [...] añadió Garcilaso imágenes tan afectuosas, y tiernas, y usó de coloridos tan vivos, que su pintura nos parece al Traductor, y á mí aun mas delicada que la del original» (p. 7); esta es la valoración de un «nosotros», el traductor y su editor, es decir, del grupo al que representan.

Después de la presentación del contexto intercultural de la traducción, de la formación del traductor, de las cualidades de Garcilaso y por lo tanto de las razones que han llevado a su traducción, la segunda parte del prólogo está dedicado al traductor y a su trabajo. Se insiste en «su buen gusto y discernimiento en la eleccion de la pieza» (p. 8): de forma implícita ya sabemos que todo el merito está del lado de la tertulia que le ha introducido a la cultura española y que, además, discutió con él las calidades del poema a traducir. Más de una vez se habla en el prólogo de «nuestro traductor», que se equipara de este modo a «nuestro poeta», Garcilaso. Este atributo no es nada casual si se tiene en cuenta el contexto de transferencia cultural más allá de fronteras lingüísticas y nacionales. Conti «se explica con tanta fluidez, y natural soltura, que á no llevar la Obra por delante el título de Traduccion, la tendria el mas advertido por original» (p. 9). Este juicio no sólo corresponde a hábitos retóricos, sino que posee un alcance de política (inter)cultural, pues una traducción convertida en original puede pretender a otro lugar en el seno de la cultura que la acoge:

12 Es más que sintomático cuando se dice brevemente de las cualidades de Garcilaso que «[c]oncurren á recomendarla muchas perfecciones, que se observan en ella» (p. 4). Se diría a primera vista que es como si su formulación neutral y reflexiva careciera de valor remarcable, si no fuera por el uso repetido del verbo «concurrir» para describir a la tertulia, a la concurrencia; resulta más que plausible considerar que Gómez Ortega refleja el resultado de lo hablado en la tertulia. 


\begin{abstract}
No es dudable el acogimiento, que logrará en Italia esta Obra. Mucho contribuirá á él en mi concepto la novedad de conocer por la primera vez á un Poeta de tanto mérito, como lo es Garcilaso; pero lo que mas admirará, me parece, que ha de ser el ver que el Sr. Conti haga hablar en Toscano á este insigne Poeta estrangero con la pureza de estilo, con que son pocos los Escritores Italianos, que hoy acierten á explicarse (pp. 9 y s.).
\end{abstract}

Según Gomez Ortega, portavoz de los tertulianos, la traducción de Conti es capaz de enriquecer la lengua italiana; pertenece, implícitamente, al mismo rango que los textos de los tre corone en su importancia para la historia de la lengua italiana; de estos, por lo menos Petraca había influido mucho en Garcilaso. Asistimos a una inversión del concepto de translatio studii y a su integración en modelos culturales de la Ilustración. Garcilaso, influido por el renacimiento italiano, vuelve ahora, en la traducción de Conti, a Italia y enriquece állí lengua y cultura. Este concepto se explicita luego a través de las voces de algunos italianos, citadas por Gomez Ortega, que lamentan la falta de conservación y cultivo de la propia lengua en sus compatriotas y hablan de la «inundacion de expresiones Lombardas, y francesismos» (p. 10). No en vano el texto cita la queja de algunos italianos sobre el enajenamiento de su propia lengua; el texto de Ortega se convierte con esa cita intercultural en una exhortación contra la hegemonía cultural de Francia en España, y conjura un eje hispano-italiano en contra del influjo francés. Al final del prólogo, se nos descubre la verdadera meta de esta publicación, que en el fondo se sirve de la traducción de Conti como mero vehículo: «[el Sr. Conti] dará á conocer á toda la República Literaria, por medio del idioma Toscano, que en nuestra Península no faltan excelentes poesías, que podamos contraponer á las composiciones métricas de las Naciones mas cultas» (p. 11). La puesta en escena de una transmisión cultural entre España y Italia se presenta como parte de una estrategia cultural más amplia destinada a integrar el Español y su cultura, a través de algunas lenguas intermedias, en el concierto europeo de las naciones ilustradas, en una República de las Letras transnacional. Hemos visto cómo la dimensión política de la traducción, en tanto que paradigma de las relaciones de fuerza interculturales, y a la vez elemento de un proceso de formación de la identidad nacional, está íntimamente relacionada con la percepción que la República Literaria tiene de sí misma, y con su lugar de fundición, la tertulia.

3. La tertulia es el espacio social que determinó en gran parte la evolución literaria de Tomás de Iriarte. Su proyecto de una Academia de Ciencias y Buenas Letras, que concede a la traducción un protagonismo importante, tiene mucho que ver con la actividad traductora de la tertulia de la fonda de San Sebastián a la que pertenece también Iriarte; casi po- 
dría considerarse su institucionalización ${ }^{13}$. Tal sugerencia no contradice el hecho de que Iriarte enfoque su proyecto de academia aparentemente en contra de la tertulia; se trata más bien de un estratagema, porque es justamente la transición de una forma de sociabilidad informal a una sociedad institucionalizada lo que quiere obtener; al mismo tiempo es un indicio de la sensibilidad de Iriarte hacia las ambivalencias y los límites de la tertulia frente a una eventual autonomización - i.e., la creación de instituciones propias - de la República Literaria ${ }^{14}$. Con su exhortación contra el supuesto diletantismo de las «tertulias de pura conversación» ${ }^{15}$, como las llama, compuestas de «meros aficionados», rechaza primero la academia literaria, parecida a la tertulia: «Uno que gusta de que le llamen Académico de número, de mérito, de honor etc. otro que desea lucir con quatro párrafos de un discurso bien o mal hilado, y por lo regular robado de algun libro Frances» ${ }^{16}$. Pero tampoco le cae bien la Real Academia Española. Tal como la concibe, la academia no debería convertirse en mero «reimpresor de libros (como la Academia Española)» ${ }^{17}$. Esta crítica demuestra que Iriarte no está dispuesto a aceptar el supuesto carácter representativo que habilitara a la Real Academia Española a pronunciarse, en exclusiva, sobre los integrantes culturales de la identidad nacional a través de su labor en pro de la tradición castiza. Al contrario, aboga en favor de revalorizar posibles aportaciones del extranjero a través de las traducción ${ }^{18}$ :

13 La propuesta de fundación de una academia significa por sí misma una forma de traducción cultural; es en este sentido que Iriarte lo comenta en sus «Reflexiones sueltas sobra la fundacion de la Academia de Ciencias y Buenas Letras»: de fundarse, se importaría en España el marco que en Francia permitió la formación de una estatuto literario profesional y conllevó al aumento de prestigio de la monarquía. Para la historia del movimiento académico en la España del siglo XVIII, véase la obra de JACOBS, H. C., Organisation und Institutionalisierung der Künste und Wissenschaften. Die Akademiegründungen der spanischen Aufklärung in der Tradition der europäischen Akademiebewegung, Francfort del Meno, Vervuert, 1996.

14 Cfr. su parodia de una academia literaria parecida a la tertulia en Los literatos en cuaresma.

15 «Academia de Ciencias en Madrid. Proyecto de fundacion. 1780-1790 etc., Madrid 15 de Oct.e de 1779, Consideraciones Que se han tenido presentes para la extension DEL PLAN De la Academia de Ciencias y Buenas-Letras De D.n Tomas de Iriarte»; AHN. Estado Leg. 3022 no 17; citado por Gisela Kaufmann, Die Akademiebewegung in Spanien im 18. Jahrhundert, Múnich, 1981, pp. 770-773, p. 772. Cfr. también ÁLVAREZ BARRIENTOS, J., «El escritor según Tomás de Iriarte: su plan de una academia de ciencias y buenas letras», en Anales de Literatura Española, 10 (1994), pp. 9-35.

16 Reflexiones sueltas sobre la fundacion de la Academia de Ciencias y Buenas Letras. De Tomas de Yriarte. 1779?; AHN Estado, Legajo 3022', no 17; citado por Gisela KAUfMANN, op. cit. pp. 778-781, p. 779.

17 KaUfMANN, op. cit., p. 780.

18 Ibíd. 
Para que se formen hombres de doctrina y gusto, es menester adoptar lo bueno de los Estrangeros, porque es dificil que de repente adelantemos lo que éllos, sin imitarlos; y para esto seria preciso traducir bien los mejores libros elementales. Esta es nuestra mayor necesidad. No nos falta ingenio, si no libros que le guien, le enriquezcan, le rectifiquen, y le abran sendas que él por si solo no puede descubrir sin ayuda del estudio. Esto está casi hecho entre los Estrangeros: solo resta trasladorlo a nuestro suelo, alterando, quitando y añadiendo con libertad lo que convenga; de suerte que unos traductores juiciosos y no serviles, lejos de corromper nuestra lengua y hacernos en todo medio Estrangeros, como sucede con muchos que hoi salen aluz, evitarian la decadencia de nra. Literatura ${ }^{19}$.

La idea de un «traductor juicioso» no está libre de contradicciones: el escritor y traductor debe actuar como instancia de selección, de control de calidad, para así no extranjerizar a la literatura y la sociedad; sin embargo, la competencia necesaria la adquiére tan sólo por el contacto con el extranjero, la cultura ajena ${ }^{20}$. Se trata, de todos modos, de una actividad de la élite literaria.

¿Cómo traduce Iriarte su imágen de un «traductor juicioso» en un proceso institucional? ¿Cuál es el papel de la traducción en esta academia

19 Ibíd., pp. 770 y s.

20 La cuidadosa y táctica argumentación de Iriarte se muestra claramente cuando éste intenta, primero, presentar el fenómeno de la traducción cultural como proceso intercultural general, y luego oscurecer las asimetrías culturales que desempeñan en gran parte un importante papel en la traducción. Así se refiere Iriarte a los antiguos intentos de fundación de una Academia de Traductores, que celebra «porque todas las Naciones, sin dexar de tener sus Escritores originales, se han aprovechado de lo que han adelantado los de las Naciones Extrangeras; y segun una máxima cierta; El que no imita, jamas será imitado [...]», (apud. KAUFMANN, op. cit., p. 770). Aun cuando todas las naciones pudieran hacer gala de sus propios escritores, sería igualmente válido que se aprovecharan de los progresos de las demás naciones. Dicho recurso al paradigma de progreso de la filosofía de la historia ilustrada, sin embargo, se ve entonces reducido, a través de la máxima «El que no imita, jamas será imitado», a un, en la opinión pública española probablemente más aceptable, principio de imitación clásico. Tan sólo en un segundo plano se menciona que España, según su parecer, sufre una verdadera demanda acumulada: «[particularmente en] «ciencias naturales y ciencias exactas, hemos sido descuidados, al paso que en las naciones estrañas han florecido los Pascales, Buffones, Lineos, Leibnitzes, Neutones, Galileis etc. etc.» (ibíd.). También la planificación oficial de la esperada gran Academia de Ciencias y Buenas Letras, su organización interna y con ella la jerarquía implícita de sus distintas actividades y campos científicos son el resultado de las afinadas reflexiones de Iriarte. Junto al equipo de traductores, la Academia debería tener un departamento de censura así como departamentos de ciencias y literatura. La ventaja de una academia que aglutina los distintos campos del saber reside ante todo, según Iriarte, en que se eviataría el título de «Mesa Censoria» que podría escandalizar a algunos autores, así como el de «academia de traductores», «[que] sublevaría a ciertas gentes, que persuadidas de que los Españoles lo sabemos todo, se escandalizarian de que se autorizase un cuerpo destinado exclusivamente a infestarnos, como ellos dicen, con doctrina Estrangera» (apud. KAUFMANN, op. cit., p. 771). 
compuesta por diferentes clases, representantes de diferentes ramos del saber, cuya relación queda aún por determinar? Lo que más llama la atención es el órden cronológico con que prevee trabajarán las diferentes secciones de la academia, orden que habrá, según él, de seguir u observar para la adquisición del saber y su transmisión: «el [ramo] de la traducción se agregaria naturalísimamente, porque las tareas del cuerpo en los primeros años serían principalmente buenas traducciones de libros magistrales y utiles» ${ }^{21}$. Así las cosas, la traducción tiene para Iriarte una significación fundamental y constitutiva, y ello en más de un sentido. Se puede, por ejemplo, considerar la parte de traducción inherente a la noción de estilo o de crítica (cualidades de las que debe disponer un «traductor juicioso»), o su papel de intermediario entre los diferentes campos científicos y/o entre la ciencia y la sociedad ( $«$ No podemos prescindir del buen gusto y de las humanidades, porque sin el $\mathrm{y}$ ' sin ellas las Ciencias se tratan de modo que todos hoyen [sic] de estudiarlas, ademas de que la substancia sin el estilo a pocos libros ha hecho generalmente famosos») ${ }^{22}$.

Es decir, que el estilo (al igual que la crítica) no es simplemente el resultado de un proceso de traducción interlingüístico, o de una transmisión de conocimientos de una cultura a otra en el sentido de un acercamiento de diferentes horizontes discursivos (eventualmente bajo el lema de un universalismo ilustrado) ${ }^{23}$; es, ante todo, un sinónimo y elemento constitutivo de la propia tarea de traducir, tarea que debe, como dijimos al principio de nuestras reflexiones, integrar la heterogeneidad de un proceso intelectual - cuanto más avanzado, tanto más irreductible- y, al mismo tiempo, tratar de acercar el saber a la sociedad. Concluyamos anotando que el concepto de Iriarte de un «traductor juicioso», con habilidad estílistica y capacidad crítica, corresponde a la imagen del escritor que, precisamente en virtud de tales cualidades, se descubre miembro de una, eso sí, controvertida élite social y cultural, dejando atrás a la tertulia y sus veleidades.

4. La Tertulia historica, y apologetica, o examen critico, donde se averigua en el Chrisòl de Monumentos antiguos, y Escritores de mayor autoridad, lo que contra Fray Geronimo Savanarola escrive el R.mo P: Maestro Fray Benito Geronimo Feyjoò en el Tomo primero de su Theatro Critico Universal. Discurs. I. §. 4. Num. II. ${ }^{24}$ de Jayme Ardanaz y Cente-

\footnotetext{
${ }^{21} \quad$ Ibíd.

22 Ibíd. El ejemplo que reconstruye es el del proyecto de traducción de la Histoire naturelle de Buffon a cargo de un miembro de la clase científica, que, en colaboración con un miembro de la clase literaria, podría ser elevado en cuanto a su nivel estilístico.

23 Como da a entender la siguiente cita de Iriarte: «Entre nosotros no sólo falta el profundo conocimiento de muchas ciencias, sino tambien el arte de escribir en estilo digno de ellas» (apud. KAUFMANN, op. cit. p. 772).

24 Biblioteca Nacional, Madrid, 2/51808.
} 
llas es uno de los muchos textos de la controversia acerca de la obra clave de Feijoo. Importa analizar este escrito en nuestro contexto porque en él se critica a Feijoo a partir del uso que éste hace de la traducción. En efecto, se puede considerar a Feijoo como precursor y ejemplo de la concepción de la traducción que analizamos a propósito de la tertulia de la fonda de San Sebastián o del proyecto académico de Tomás de Iriarte: fuente de conocimiento y medio de difusión. Desconfiar de la traducción y de su uso por Feijoo significa, pues, rehusar sus mismos presupuestos ideológicos; esto es, rechaza la traducción como uno de los fundamentos de una República de las Letras transnacional cada vez más autónoma, a la vez que menostiene el concepto de Ilustración como proceso de comprensión intercultural, y cuestiona la imagen del escritor como «traductor juicioso». Si anteriormente analizamos el papel de la tertulia (o de la academia) en el proceso de traducción, se trata ahora más bien de analizar la recepción concreta de una traducción en una tertulia; es decir, después de la producción, habrá que considerar la otra vertiente del proceso literario: la lectura, la recepción crítica de un texto. Valor añadido para dedicarnos a este texto es el hecho de que la crítica de Feijoo tiene lugar en el seno de una tertulia, dentro de la sociedad a cuyo desengaño quería contribuir el autor. Por lo demás, el desengaño como uno de los objetivos del Teatro Crítico Universal representa, a su vez, una suerte de traducción; y ello en la medida en que los fenómenos discutidos deben trasladarse de un código lingüístico o de un discurso a otro; por ejemplo, de un discurso religioso o mágico, a uno histórico o de las ciencias naturales. El hecho de que en esta tertulia se discuta y por lo tanto se refleja uno de los conflictos más importantes de esa época y uno de los tópicos de la Ilustración - a saber el conflicto entre el despotismo ilustrado y la primacía religiosa, conflicto que determina a su vez de forma decisiva la cuestión de la traducciónes una razón de más para discutir este texto.

El marco narrativo - una disputa entre el despotismo ilustrado y la autoridad religiosa acerca de la adjudicación de $\operatorname{cargos}^{25}$, así como la consiguiente institución de una comisión de arbitraje que se compone de dos representantes por cada bando y se reúne por la noche en tertulia-, determina y contextualiza hasta cierto punto la discusión del texto de Feijoo, y llama nuestra atención a la verdadera, pero siempre silenciada apuesta de las discusiones sobre la traducción y su papel en el Teatro Crítico Universal. Pese a que nunca se nos informe del contenido de los debates políticos (con trasfondo religioso) sobre la regalía, el lector participa en el debate sobre la obra de Feijoo como un miembro más en las tertulias ves-

25 «porque el Governador, y la Ciudad decian, que mientras no se les mostrasse Zedula, Privilegio Real, ò Titulo legitimo, siempre tendrian por propia regalìa del Patrimonio de su Magestad, la eleccion de aquel Ministro, y por intrusion, vsurpacion, y violencia la authoridad, que se avian tomado el Obispo, y Cabildo» (p. 5). 
pertinas. En concreto, se increpa a Feijoo por su presentación de la vida de Savanarola; se trata de la censura de Joseph Medrano ${ }^{26}$ contra Feijoo por haber mantenido que las revelaciones que supuestamente constituyeron la base de las profecias políticas de Savanarola no habrían sido más que el producto de una amplia red de informadores y corresponsales mantenida por Savanarola. Medrano justifica esa opinión con «tan grave fundamento, como la Revelacion, que la Beata Virgen Columba tuvo de la Gloria de Savanarola, y sus dos Compañeros, escrita por vn Autor, que sobre ser Principe de la Iglesia, merecia veneracion, y credito por su Doctrina, y piedad» (pp. 15 y s.).

Esta presentación nos descubre desde el inicio la verdadera piedra de toque de la tertulia, al menos desde el punto de vista de los que se pronuncian en contra de Feijoo: «revelacion» y «doctrina», ésta deducida de aquélla, son el garante de la autenticidad y de la verdad; «veneracion», «credito» y «piedad» describen la actitud correspondiente por parte del lector. Sobre tal fundamento, construye una parte de los tertulianos su crítica de la traducción y del saber que se ha ganado a partir de ella: «y me parece que haze evidencia, de que el buen Padre Feyjoò, trasladò à bulto, sin circunspeccion, y examen, lo que hallò escrito en no sè que Autor Francès» (p. 7).

De esta forma, la traducción está vinculada directamente al conflicto inicial, generador del texto, acerca de las fuentes e instancias de autoridad en la sociedad española del siglo XVIII. Resulta muy interesante destacar que los tertulianos, de los que forma parte también Ardanaz y Centellas, se atribuyen el derecho a censurar a Feijoo por su condición de eruditos y miembros por lo tanto de la República de las Letras (y no en base a su condición de delegados del poder secular y religioso) ${ }^{27}$. A pesar de su posterior condena de Feijoo, incluyen al escritor como traductor e ilustrado en el cuestionamiento de la autoridad, considerándolo como uno de sus posibles representantes; hablando de él, hablan en parte de sí mismos y del lugar que ocupan en la sociedad. Los tertulianos se preguntan por la legitimidad del texto de Feijoo, y examinan en qué medida coincide con las

${ }_{26}$ En su libro Vida de la admirable Virgen Santa Inès de Monte Peliciano \& (?) altissima Esposa de Jesus, favorecida Sierva de Maria Santissima, amada Hija, y perfecta imitadora del Inclito Patriarcha Santo Domingo de Guzman; y vn Compendio de las de el Glorioso Confessor San Dalmacio Monèr, y la Esclarecida Virgen Santa Columba de Reati, todos de la Orden de Predicadores. Por el Padre Presentado Fr. Manuel Joseph de Medrano, Predicador General y Choronista de la misma Orden (p. 14).

27 Así se lee en el prólogo: «Amigo Lector, los Discursos que contiene este Papel, tuvieron motivo en vna casualidad, y fiel examen en la balanza de Autores de mayor exepcion; y de quatro Sugetos igualmente eruditos, y prudentes. Dirigense à dejar en el estado, que antes tenia la fama del cèlebre Fr. Geronimo Savanarola, de la Orden de Santo Domingo, cuya culpa, ó cuya inocencia, no està aun bien determinada entre los Autores» (p. 3). 
autoridades en uso de la sociedad ${ }^{28}$. Por medio de este procedimiento, y no está de más recalcarlo, afirman, aunque involuntariamente, la existencia de un nuevo grupo social, de una nueva y poderosa voz en la sociedad de la que, en cierta medida, forman parte. Una de las paradojas de este texto es que los tertulianos exijan al escritor que se someta a la autoridad, cuando su propio discurso (hablan como eruditos, es decir, como miembros de la República Literaria, y no con la voz de la autoridad que se les ha atribuído) contradice esa petición que creen poder formular una vez han realizado el análisis textual (véase, para la metáfora del tribunal, la nota 28).

Esta constelación conflictiva de la tertulia se agrava al anteponerle una norma, la de un consenso como base de la autoridad bajo el signo de la unidad del altar y del trono. Esta norma se refiere a primera vista a la discusión acerca de la regalía, pero afecta al mismo tiempo la polémica sobre Feijoo, cuyas interferencias con el debate que determina el marco narrativo, y por lo tanto el conjunto del texto, se han puesto ya de manifiesto:

28 Incluso asistimos a una multiplicación de las instancias de autoridad que se contradicen a ratos en el transcurso del texto, a un cuestionamiento del poder, de la autoridad y del saber colectivo y de su fuerza legitimadora. A este respecto juega un papel destacado la atribuición equívoca de las metáforas del tribunal o de la censura. Así se dice de Feijoo que «como si fuera el Tostado, Juan Pico Mirandulano, Justo Lipsio, ù otro de aquellos Heroes, que se hizieron famosos por su vniversal Erudicion, se toma el caracter de Juez en todas materias, de Difinidor en todas disputas, y de Padre Maestro en todas ciencias, difiniendo con varia censorìa, y tratando de preocupacion, todo lo que no es vna vil deferencia à su dictamen; y esto, señor mio, es presumir mucho, y saber poco» (p. 8). En otro lugar del texto se cuestiona si el Teatro Crítico Universal de Feijoo posee el carácter de un tribunal de la Rota, esto es, si en general ha usurpado la autoridad eclesiástica. De ahí se sigue que la tertulia se defina contra el supuesto poder inquisitor de Feijoo: al presunto monólogo de Feijoo antepone el principio dialógico de la tertulia, con lo cual no tan sólo entra en conflicto con la subordinación a la autoridad de la Iglesia, exigida y descrita por su colega y autor de la obra como tribunal y censura - «pero en todo caso, pongo todo quanto en este Papel và escrito à los pies de la Santa Iglesia Catholica Romana, y lo sujeto à la censura, y juyzio de sus infalibles determinaciones. VALE» (pp. 3 y s.) -, sino también con su concepción del tribunal tratada repetidamente en la discusión, cuando se describe al autor a la vez como»juez» y oyente de la tertulia - «Hallème en estas conversaciones, ò Tertulias, como oyente, y como Juez: y viendo que este punto se examinò en ella, quanto permite la humana fragilidad, no quise privarte [amigo Lector] del gusto de la erudicion, que contienen» (p. 3)-. Incluso la metáfora judicial, la escenificación de la tertulia como tribunal toma en el texto un cariz problemático en la medida en que el proceso de deliberación - del juicio- oscila entre un pronunciamiento jerárquico y una expresión igualitaria o democrática. Ejemplo de esta dubitación es la secuencia final del texto. Como alternativa a las pretensiones de los tertulianos, de que Ardanaz y Centellas ejerca de juez, este propone una vía de decisión protodemocrática, en cuyo final predominará de modo previsible la crítica a Feijoo. 
Pero ni el Obispo, ni el Governador quisieron que esta se hiziesse por modo de querella, sino como consulta, que deseaba para el acierto, la providencia de tan grandes Ministros; porque assi creìn salvar mejor su authoridad, y sin las vozes de pleyto, y discordia, que ò̀an como impropias, respecto de su amante, y buena correspondencia. Nombraronse los Diputados, que estrechando los fundamentos de amigable vnion, vinieron juntos, y aun tomaron vna misma Posada en esta Corte, à donde llegaron el dia de Carnestolendas (p. 6).

Al principio asistimos, en nuestra calidad de lectores, a la «santa conversación» (p. 6) de los miembros de la comisión, que charlan a propósito de la lectura del Aprecio de la Divina Gracia, del padre Eusebio Nieremberg, «conformando su ansia de saber, con la Virtud, que inspira al Santo tiempo de la Quaresma». La polémica acerca del Teatro Crítico Universal, y en consecuencia acerca de la aparente disolución de la unión entre saber y virtud, se percibe como una alteración de ese "santo entretenimiento», alteración que habrá de superar en ocho «tertulias» - así se llaman los capítulos de este libro- para poder volver después a la lectura de Nieremberg: «y Don Miguèl dixo: Yà, gracias à Dios, hemos dado fin à nuestra prolixa controversia, y podemos continùar, desde mañana, la vtilissima Leccion del Padre Nieremberg» (p. 57). No obstante, es más que dudoso si la verdad única puede recuperarse tan fácilmente, una vez que ha entrado en un proceso de diseminación y proliferación cuya línea de fuga es la tertulia.

El instrumento más importante de la crítica de Feijoo es su relación con las fuentes francesas, la comparación de los textos y las traducciones, el llamado «cotejo» (p. 20). Desde el inicio, Miguel, uno de los tertulianos, intenta demostrar que el gesto de autoría de Feijoo no es sino usurpado y por lo tanto ilegítimo: «este Padre Maestro nos vende por sudores suyos los trabajos agenos» (p. 8).

Pues sepan V.ms. que todo lo que el Padre Cathedratico de Oviedo nos ofrece como parto de sus fatigas, no es otra cosa, que vna traduccion de varias obras Francesas, que el Santo Padre ha hilvanado en su Libro. Y porque no piensen V.ms. que hablo de memoria, vamos à la Bibliotheca Real, y con el poco trabajo de registrar algunos Tomos del Journal de Scavans, y de las Memorias de Treboux, veràn V.ms. desempeñada mi proposición (p. 9).

La traducción como razón de la usurpación de una autoridad: ese punto de vista tiene su lado político, porque considera también al texto traducido, al objeto de la traducción, como un ataque a la autoridad nacional o religiosa. En segundo lugar, y más allá de la problemática de autoridad que se pueda ejemplificar en ella, la traducción se convierte en la expresión de una heterogeneidad del saber, prefigurando así la realidad discursiva moderna. En el contexto de la Tertulia historica y apologetica se la percibe como una amenaza que hay que combatir a partir de una perspectiva holista: lo que más molesta a Miguel en el Teatro Crítico Universal es la 
gran variedad y número de los temas tratados; lo califica de «Libro de Tiquis michis, tocando puntos Toto Coelo distantes, como dicen, y algunos, no solamente impropios, sino indecentes à su estado» (p. 8). Tamaña heterogeneidad es irreductible sin la mediación de la traducción entendida en todo su alcance. El debate acerca de la traducción se convierte en el más fundamental de los cuestionamientos de la difícil relación entre intertextualidad - los textos traducidos, la pluralidad del saber-y autoridad -el texto canónico y su exégesis-, tal y como la observamos al ejemplo de la «santa conversación» sobre la divina gracia a raíz del texto del padre Nierenberg.

Las dos propiedades que acabamos de describir confieren a la traducción, en tercer lugar, una fuerza performativa que se acompaña, en la opinión de algunos tertulianos, de una actividad subversiva, como trasciende ya de la cita anterior, donde queda advertido que el tratamiento feijooniano de asuntos muy diversos, «intraducibles», e irreductibles a un sólo lenguaje o discurso, hiere las límites tradicionales de estamento o de sexo («impropios, sino indecentes a su estado»). El ejemplo al que alude don Miguel son los textos de Feijoo sobre la mujer, a su juicio demasiado liberales: su propia mujer, Margarita, «que en nuestra Ciudad era el exemplo de la modestia entre las señoras; y del amor, y respeto conjugal entre las casadas» (p. 10), habría, en una «visita» (p. 11) ${ }^{29}$, oído hablar de Feijoo, hecho que le hubiera motivado a leer los textos del mismo. Después de esta experiencia, habría empezado a faltar a sus obligaciones familiares, a aprender latín y francés, a preocuparse por la filosofía de Descartes. Podemos resumir diciendo que Margarita se habría dirigido hacia Feijoo, hacia la traducción y el espacio cultural ajeno ${ }^{30}$. La traducción, que según la opinión de la tertulia conforma la base de la obra de Feijoo, se revela como el caballo de Troya que contribuye potencialmente a la revolución del status quo social y político. Se teme una dinámica cultural que se refiera no sólo a la traducción y su poder subversivo, sino también a la tertulia como espacio de transmisión del saber ajeno.

Otro ejemplo del poder subversivo del saber que Feijoo ganó a través de la traducción es la problemática del pueblo, discutida al final de la tertulia. Otra vez es la religión el soporte sobre el que descansa la argumentación de los críticos con Feijoo: «Y dexando aparte, porque no es de nuestro proposito, si la voz del Pueblo es tan engañosa como el Theatro Critico afirma; pues para dudarlo basta saber, que el Evangelio nos dice,

${ }^{29}$ Téngase en cuenta de nuevo aquí el papel de la tertulia - la visita es uno de sus muchos sinónimos- como lugar de intercambio cultural.

30 Lo que fue abandonado según los críticos de Feijoo es la modestia con la que se describió no ya sólo el papel de la mujer, sino previamente también el del escritor. «La modestia es el mejor caracter de qualquier Escritor»(p. 8). Según esta concepción, la traducción infringiría de raíz el precepto de humildad. 
que la voz del Pueblo de Jerusalèn estuvo siempre de parte de Christo» (p. 50) ${ }^{31}$. Santiago radicaliza este argumento religioso con uno patriótico, sosteniendo que la crítica feijooniana contra Savanarola, cuya ciega admiración por el «vulgo» critica, constituiría en toda regla un ataque contra el orden social en su conjunto, porque, siempre según él, allí se encuentran representadas todas las capas sociales -i.e., el pueblo que comprende al vulgo - que apoyarían esa fe popular, una fe que en consecuencia devendría elemento religioso de la identidad nacional:

no solamente el Pueblo, sino tambien los Principes, los Reyes, los Consejeros, los hombres Doctos, y aun los Santos estimaron à Sabanarola. Con que si el P. Feyjoò entiende por Pueblo, lo mismo que Vulgo, que es lo que parece significan sus expresiones, haze Vulgo à los Santos, doctos Consejeros, Principes, y Reyes. Si por Pueblo entiende vna multitud confusa de toda classe de gente, Plebeya, y Nóble, tampoco viene al caso este exemplo; porque Sabanarola siempre tuvo contra sì à muchos poderosos, y Nobles de Florencia. (p. 54).

La intención de Feijoo de desengañar al pueblo no se habría realizado por sus méritos, sino, según su propio parecer, gracias a la tertulia de sus críticos. Es ésta la razón fundamental que les lleva a hacer públicas sus deliberaciones:

Con esto se despidieron los Amigos, señalando su Posada, para bolver à la mas provechosa Leccion del Padre Eusebio: Diles palabra de acudir, y meditando conmigo, que era lastima, que el Publico no gozasse el erudito desengaño de nuestras Tertulias [el subrayado es mío], determinè dàrle à la Prensa, no sin esperanza de que estos Discursos merezcan el agrado, y la aprobacion de los Lectores desapassionados. (p. 58).

Esa transformación de la tertulia en texto dice mucho del carácter representativo que pretende conferirle el autor, Ardanaz y Centellas, en relación con la sociedad en general. No es azaroso aquí el empleo de la expresión «el Publico» en el sentido de una opinión pública general, lejos ya de la del vulgo que había sido el destinatario del texto de Feijoo. En este contexto, resulta más que interesante que la tertulia ejemplifique el resultado pedagógico que quiere realizar en sus propias filas a través de la figura de una «mise en abyme»: se nos presenta el desengaño de aquellos miembros de la tertulia que, durante mucho tiempo, habían defendido a Feijoo. Antonio, por ejemplo, procede a una autocrítica y confiesa que «hasta aora estaba engañado» (p. 53), porque había considerado el Teatro crítico universal como el mejor libro en lengua española.

A pesar de estas críticas aparentemente tan fundamentales a la traduc-

31 La circunstancia de que el pueblo de Jerusalén exigiera la muerte de Cristo no sería aquí un argumento contrario (p. 51). 
ción, la tertulia se esfuerza en distinguir entre una buena y una mala traducción; la distinción se opera a partir del criterio de selección del texto traducido (es decir, de su calidad), así como del prestigio de la lengua original $^{32}$. La legitimidad de la traducción se mide conforme al prestigio y a la importancia del autor que se traduce ( $«$ Segundo: $\mathrm{Si}$ es cierto, que dichas clausulas son trasladadas al pie de la letra del docto Maestro Gabrièl Naudè; y què credito merece este Autor en la materia que tratamos» [p. 17]). Como éste es un criterio que no guarda mucha relación con el acto lingüístico de la traducción, aunque sí con criterios epistemológicos más generales, se evidencia de nuevo hasta qué punto la traducción es, en el contexto de las discusiones de la tertulia, la alegoría de una problemática fundamental de la sociedad de aquel entonces, sometida al profundo cambio de cómo situarse frente a un saber heterogéneo y plural.

Sin embargo, el intento de definir muestras cualitativas para la selección de los textos a traducir fracasa; por un lado, no siempre pueden los tertulianos ponerse de acuerdo sobre un estándar cualitativo - desde el punto de vista de los adversarios de Feijoo, por ejemplo, la fama de un Naudé no puede competir con la de autores religiosos ${ }^{33}$-; por otro, se encuentran con el problema de la selección cuantitativa de textos relevantes para citar como testigos de la autoridad y la transcendencia de un texto ${ }^{34}$. Como si

${ }^{32}$ Consideran aquí los críticos de Feijoo que el latín aventaja, por ejemplo y en virtud de su antigüedad y prestigio cultural, a la lengua francesa.

33 En tal sentido los defensores de Feijoo intentan demostrar, tras haber comprobado en un diccionario biográfico de Luis Moreri del año 1698 unos datos biográficos de Naudé, que este autor, fuente de Feijoo, ocupa en efecto el rango de una autoridad. Miguel les contradice sosteniendo que incluso los más grandes autores pueden haber cometido errores, y que además, Naudé se habría dedicado al asunto tan sólo de forma cursoria (pp. 21 y s.). Por el contrario, los adversarios de Feijoo argumentan con una fuente religiosa de la vida de Savanarola y del carácter sagrado de sus profecias, intentando de este modo desacreditar el texto de Feijoo por una lectura normativa de índole religiosa-transcendental, jerárquica. Por lo demás, se cita de nuevo que el Padre Medrano articula su crítica del Teatro crítico universal «con tan grave fundamento, como la Revelacion, que la Beata Virgen Columba tuvo de la Gloria de Savanarola, y sus dos Compañeros, escrita por vn Autor, que sobre ser Principe de la Iglesia, merecia veneracion, y credito por su Doctrina, y piedad» (pp. 15 y s.). Otros autores citan como fuente las reglas de la orden de los Dominicos, que hablan en favor de Savanarola, y son para Miguèl de más peso que las de Naudè; Feijoo «debiera no atropellar Authoridad tan venerable» (p. 24). Aun antes de revisar el juicio de Juan Francisco Mirandulano sobre Savanarola, Alonso muestra que se debería leer este texto con «veneracion, porque tiene al principio vn Privilegio de Leon X. y vna Censura de Alexandro VI. en que favorece las Obras de este Principe; y no ignoran Vs.mds. que vna de ellas, es la Apologia por Sabanarola. Pero vamos leyendo» (p. 42). Se recurre aquí a la autoridad papal. Se dice además del libro que «refiere Revelaciones, Profecìas, y Milagros, que confirman, ò dàn mucha fuerza à estos elogios» (p. 43).

34 Una vez examinada la obra de los autores mencionados en la nota 33, es el turno ahora de San Phelipe Neri, Phelipe de Comines, Juan de Vitrian, y Juan Francisco 
los representantes de la ortodoxia no estuvieran muy seguros del carácter revelado de la verdad en el «caso Savanarola», van multiplicándose sin límite los textos de referencia religiosa, que puedan servir para descalificar las afirmaciones de Feijoo sobre Savanarola. Los tertulianos llegan, en el transcurso del cotejo y de la búsqueda de las fuentes de la revelación que se manifestara en el texto - la legitimidad de la palabra supuestamente revelada-, a un abismo de citas e intertextos siempre nuevos que no son más que meras traducciones destinadas a transmitir la revelación en una orden ininterrumpida. Pero, ¿dónde encontrar el texto original, la fuente de la revelación, frente a la red circular de los muchos intertextos que se discuten en la tertulia? Llegamos, por segunda vez, a la dificil relación entre intertextualidad y autoridad. Aparentemente, la verdad revelada no puede ser deducida de los textos a través del mero cotejo (que no conduce a más que a otro texto), sino sólo a partir de un a priori exterior al texto, de un artículo de fe.

No menos problemático resulta el intento contrario de partir, - cuando se quieren forjar unas categorías para apreciar la calidad de una traducción-, no ya del texto por traducir o del renombre de su autor, sino del carácter representativo y de la importancia del grupo de los críticos, de los hombres de letras que lo enjuician. En una de las narraciones intercaladas el argumento «esta razon la daba vn Autor muy clasico» se refuta por el siguiente: «vn punto tan grave no se govierna por vn Autor solo, ni aun por muchos, si los fundamentos no son firmes. Debiera el que Vs. mds. citan, responder à los gravissimos argumentos con que los hombres mas graves de todas Naciones, acusan [...]» (pp. 30 y s.). Pero el intento de constituir el grupo de los «hombres mas graves de todas Naciones» constituye tan sólo una dislocación del debate sobre la legitimidad y la autoridad que se discutía en la tertulia a partir de la traducción. Es más; si aceptamos que la Tertulia historica y apologetica, cuyas discusiones retratamos, para su propia dilucidación equivale al grupo de los «hombres mas graves de todas Naciones», veremos que, con la mera constitución de una élite, no se pueden disolver automáticamente todas las contradicciones epistemológicas que surgen en esta época. Partiendo de la discusión literaria hemos llegado otra vez a la cuestión de la sociabilidad y la urba-

Mirandulano; a pesar de que en la tertulia se lanza la pregunta de cuántos testigos se necesitan para proceder a un juicio, proceso en cierto sentido parecido al cotejo (p. 40), y que se les quitan a algunos tertulianos las ganas de tener que atender a más interpretaciones (pp. 42 y s.). Don Miguel debe apaciguar los ánimos de los tertulianos: «Sosieguese V.md. dixo Don Miguèl, que en estas cosas, es sospechoso dexar algo, sin examen, y aun faltan Bzobio, y Oderico Raynaldo, que el Padre Medrano alega» (p. 43). Luego se trata a otros autores que Medrano no ha citado, pero que se han ocupado igualmente de Savanarola, como Enrrico Spondano, Guichardino, Mariana, e Illescas con su Historia Pontifical. 
nidad, de la tertulia como una de las manifestaciones de la República Literaria.

Según Ardanaz y Centellas, Feijoo debería haber considerado en su traducción de Naudé tres aspectos: «la verdad de la historia», «los testimonios de los hombres mas Ilustres de la Iglesia», así como «todas las buenas leyes de vrbanidad, polìtica, y religiosa» (p. 52). Es una petición muy paradójica, pues tanto el marco narrativo como la discusión de la tertulia demuestran que el consenso sobre lo que son «todas las leyes de vrbanidad, politica, y religiosa [el subrayado es mío]», esto es, el consenso entre el altar y el trono que se evoca al principio del texto, ya no existe; que su crisis es justamente el objeto de ese texto. Y si Ardanaz y Centellas en su calidad de moderador apenas logra sacar a colación la pluralidad de las diferentes opiniones de la Tertulia historica y apologetica en un proceso consensual de búsqueda'de la verdad a través de un análisis textual, un cotejo - a coste, otra paradoja más, de eliminar y descalifiar el texto verdaderamente plural y heterogéneo de Feijoo-, no puede evitar que en el transcurso de la discusión este último criterio para determinar una calidad textual y social, las ya citadas «leyes de vrbanidad, polìtica y religiosa», parezcan al contrario como índice de inautenticidad y por lo tanto como un inadecuado paradigma de crítica literaria. Una carta de Luis de Salazar y Castro, «Principe de Historia, de la erudicion, y el estilo» (p. 12), que defiende a Feijoo, citada por los adeptos de Feijoo en la tertulia, es rechazada por sus adversarios bajo el pretexto de las «leyes de vrbanidad» «porque la Carta, si bien se considera, no es aprobacion, sino cortesania de Don Luis» (p. 12) ${ }^{35}$. Que esas «leyes de vrbanidad, politica y religiosa» han perdido su carácter normativo, se hace patente ya en el hecho de que en esta tertulia se nos remite - narrándolas- a otras tertulias; se nos muestran otros ejemplos de una urbanidad distinta al ideal de Ardanaz y Centellas, donde destacan sobre todo el intercambio, la apertura hacia el extranjero, hacia la heterogeneidad. Basta con citar el ejemplo de la «visita» en la que participa la mujer de uno de los miembros de la Tertulia historica y apologetica que, tras esta toma de contacto, se convirtió en lectora de Feijoo. Por medio de los fenómenos contemporáneos de urbanidad o de sociabilidad que se representan en la Tertulia historica y apologetica, y pese a que Ardanaz y Centellas no quiera admitirlo, resurge entonces lo que había sido eliminado del discurso social anteriormente.

El debate tertuliano sobre la traducción ha mostrado muy claramente

35 Una diferencia que se manifiesta más profunda en una narración intercalada cuando un miembro de la corte describe en dos ocasiones distintas las nobles cualidades de un pretendiente de un modo diametralmente opuesto: «quando V.md. me preguntò, hablè como Cavallero, y aqui depongo como testigo. Este es el caso, y su aplicacion muy facil» (p. 13). Se trata de una interesante comparación, en la medida en que pone a Feijoo al mismo nivel que un pretendiente que tan sólo ha trampeado con sus peticiones. 
la dimensión social de ésta. En este debate, a primera vista literario, se trata en realidad de «todas las buenas Leyes de vrbanidad, polìtica, y religiosa», de una reorganización profunda del orden social, en un momento (y es precisamento esto lo que manifiesta el texto), donde los fundamentos políticos y religiosos de la sociedad, y con ellos las autoridades que se rebasan en ellos, empiezan a desmoronarse. La duplicidad de la traducción, que pone en relación lo propio y lo extraño - ino consideran los tertulianos a Feijoo como un extranjero, como un medio, a través del cual se puede percibir una voz desconocida? - nos revela tales rupturas. Con su autoridad «prestada», la traducción es capaz de perturbar el sistema epistemológico y mental tradicional aparentemente tan cerrado, de descubrir las asimetrías y asincronías en la relación de la sociedad con un saber cada vez más heterogéneo, una sociedad en realidad mucho menos homogénea de lo considerado habitụalmente, y que es capaz de responder a la novedad de forma muy diversa.

El intento de sustraerse a la ambivalencia, a la heterogeneidad de la configuración moderna del saber con el recurso al discurso religioso, y el intento consiguiente de restablecer una forma de sociedad equivalente - la comunidad de la «santa conversación»-, tal intento puede Ardanaz y Centellas llevarlo únicamente a cabo inmunizando, aparentemente de forma democrática, los miembros de la tertulia contra la irrupción del extranjero, contra la traducción. El complejo debate, que escenifica la tertulia y nos dice algo sobre los avatares y las modalidades de la constitución de la República de las Letras, amenaza sin embargo con traspasar el límite que había intentado edificar el marco narrativo cuando invocaba un consenso secular.

5. En último lugar queremos presentar un ejemplo donde ya no sean la iglesia o la religión las que garanticen la unidad del saber, sino el despotismo ilustrado. Donde Ardanaz y Centellas establece todavía un discurso pseudodemocrático y rehúsa, pese a reconocerlo como propio, el papel de árbitro, nos interesa ahora un ejemplo en el que sea el Estado quien asuma el arbitraje y desempeñe el papel de «traductor juicioso», el de una institución de control del saber. Este ejemplo es sumamente interesante en cuanto a la traducción se refiere, puesto que no aparece aquí como medio de acercamiento a la modernidad europea; no se trata en lo que sigue de la traducción como proceso de mediación, de concienciación de las diferencias interculturales; antes bien, la traducción se revela ahora como proceso paradójico de homogeneización, como instrumento de una política hegemónica. Hablamos del discurso de Joseph Vargas Ponce sobre el Elogio del rey don Alonso el Sabio que leyó ante la Real Academia Española en 1782, y que fue premiado por la misma institución ${ }^{36}$. Expone su peti-

36 Joseph VARgas PONCE, Elogio del Rey Don Alonso el Sabio, premiado por la Real Academia Española, en junta que celebró el día 15 de octubre de 1782, in: Me- 
ción de una academia de las ciencias a través de una digresión histórica sobre el mérito de la escuela de traductores de Alfonso el Sabio.

Antes de insistir en los logros de Alfonso el Sabio en los distintos campos del conocimiento - a saber, entre otros, la homogeneización de la jurisdicción, la historiografía esencial para la comprension de la propia nación, la matemática y la astronomía -, logros que se habían realizado, como no se cansa de repetirlo Vargas Ponce, antes del renacimiento europeo (p. 401), cabe destacar la base de tanta actividad: la existencia de un idioma homogéneo. Para su desarrollo (sobre todo en el contexto político y linguístico del siglo XIII) hacía falta un trabajo de traducción intralinguística en doble sentido : con respecto a la integración de los conocimientos árabes en la propia cultura (proceso que califica de naturalización ${ }^{37}$ ), y en relación a una homogeneización de la lengua. Esa actitud de cuidado y mimo hacia la lengua, que se considera fundamental para el desarrollo científico y en miras a una cierta resonancia de España en el extranjero, se convierte a finales del siglo XVIII y a los ojos de Vargas Ponce, en una proeza europea avant la lettre:

Yacia la lengua española, si era alguna, en el mayor desaliño, incultura y barbarie. [...] Nuestro monarca Sabio remedió este descuido, juntando en un nuevo lenguajes, ya las expresiones de Píndaro y Aboulola, ya las de César y Ataulfo. Á su esmero se debe el idioma más completo, más rico, más armonioso, [...] Idioma que es sin duda el primogénito del latino, y el que más se acerca á la abundancia ática. Idioma que lleva tantas ventajas á todos los vivos de la Europa (pp. 385 y s.).

También elogia el trabajo de traducción propiamente dicho de la academia alfonsina:

Para darles todas las [mejoras] que permitia la instruccion de aquel siglo, llamó Alfonso á su sombra cuantos profesores cristianos, judíos, árabes, de España, de la Europa, del Oriente, pudo juntar su magnificencia. Congregados en la metrópoli para la vasta empresa, él los presidia, y en su ausencia sus maestros. Él enmendaba sus trabajos; él mandaba hacer versiones del hebreo, del caldeo, del árabe; él era el censor; él los acompañaba a observar, para lo que los tenía junto á su persona; y él, finalmente, formó la primera sociedad que para el progreso de las matemáticas, ó lo que es lo mismo, para bien del género humano, vió Europa (p. 396).

morias de la Adademia Española, 1, 2 (1870), pp. 373 y ss. Madrid: Rivadeneyra 1870. Para Vargas Ponce cfr. DURÁn LóPEZ, F., ROMERo FERRER, A. (eds.): «Había bajado de Saturno». Diez calas en la obra de José Vargas Ponce, seguidas de un opúsculo inédito del mismo autor. Cádiz, Servico de Publicaciones de la Universidad de Cádiz, Instituto Feijoo de Estudios del Siglo XVIII de la Universidad de Oviedo, 1999.

37 Con ello enfatiza la paradoja de que los representantes de la cultura árabe eran considerados como «naturales que miraba como extraños [...] Alfonso, apénas rey, concibió el vasto designio de hacerlas transmigrar á sus verdaderos naturales; pero ántes era necesario darles expresiones para tratarlas con decoro» (p. 385). 
Reconsidera, como se puede observar, la escuela de traductores alfonsina ante el contexto de finales del siglo XVIII: subraya que los científicos reunidos en la academia vinieron de las cuatro partes del mundo, reclamando de esta manera el carácter universal de sus actividades. Insiste también en el aspecto interconfesional, una apuesta aún utópica en el siglo XVIII.

La traducción aparece de esta manera como una cuestión de poder, i.e. de la autorización de un saber ${ }^{38}$. Si vincula su elogio de la escuela de traductores a la petición de una academia de ciencias, no se puede hablar, en palabras de Vargas Ponce, de una imitación de uno de los muchos proyectos académicos que florecen en el siglo XVIII en Europa, más bien al contrario. Lo principal de su discurso es, pues, afirmar que la academia de traductores fundada por Alfonso sería la «primera sociedad» que para el bién de la humanidad se hubiera constituido en Europa.

Tal como es presentada por Vargas Ponce, la gradación de las diferentes actividades de Alfonso el Sabio tiene una vocación eminentemente cosmopolita y su enumeración suena como un eco lejano de una célebre cita de Montesquieu:

Con su poesía se sirvió á sí, con su derecho á su reino, con su historia á su nacion; pero con sus trabajos astronómicos á sí, á su reino, á su nacion, y á todos los reinos y á todas las naciones. [...] Á lo ménos, no se le podrá disputar la gloria de ser el primer europeo que se aplicó á unas tareas tan útiles, de ser el padre de la astronomía en nuestro continente (p. 397).

Vargas Ponce incluye la traducción en la gama de las nociones epistemológicas del siglo XVIII: habla de su papel fundamental al permitir el conocimiento y su transmisión, y menciona su dimensión de política cultural. Al final compara los logros de Alfonso $\mathrm{X}$ con el de otros sabios europeos de los siglos XVII y XVIII, como Descartes y Newton. Tan sólo con Leibniz se admitiría una comparación, por la variedad de sus actividades, equiparables a las de Alfonso el Sabio, aunque no alcanzaría la altura de éste. Esta comparación se realiza al considerar el papel del lenguaje para ambos eruditos: «No os intimideis, que, aunque el único capaz de disputarle, no será suyo el triunfo. Si él presenta el vasto impracticable proyecto de una lengua universal, oponedle la realidad de un idioma hermoso que se dilata por ambos mundos» (p. 399).

${ }^{38}$ En las notas a pie de página de su edición, Vargas Ponce remite a libros -que Alfonso hizo traducir- en los que se menciona la intervención del propio rey en las propuestas de traducción de sus autores (pp. 426 y s.). Concuerda con ello que, en otro texto de 1793, en la Declamación contra los abusos introducidos en el castellano, Vargas Ponce abogara por la instauración de una Mesa Censoria en la Academia, «avocándose el conocimiento y censura de las traducciones»; cfr. CHECA BELTRÁN, J., op. cit., p. 601. 
La traducción intralinguística con el fin de modelar la lengua española, la asimilación del saber ajeno en la traducción organizada por el Estado llegan a ser, según se ha visto, la base de una concepción del universalismo muy semejante a la de un imperialismo cultural. Dicha variante de una política hegemónica queda por lo menos tan lejos de un unversalismo cosmopolita, como del concepto de una lengua universal mencionado al ejemplo de Leibniz. La noción de traducción, en el caso de Vargas Ponce, no sirve, como se hubiera podido creer al leer algunas citas, a la transmisión gradual, paso a paso de conocimiento - del sujeto, a la nación, a la humanidad - hasta llegar a lo más general, sino que se sometee a una pretensión hegemónica, incluso universal, como, por ejemplo, no la encontramos en el caso del proyecto académico de Iriarte.

6. Los cuatro modelos de traducción que presentamos sucintamente movilizan, de forma más bien implícita, todo un pensamiento sobre formas de convivencia y sociabilidad en la medida en que la cuestión propuesta por la traducción acerca de la relación con el otro, el extraño, alcanza no solamente dimensiones epistemológicas sino igualmente éticas y políticas en el sentido de un proceso, a veces conflictivo, de la formación de una identidad. La República de las Letras, que observamos al ejemplo de algunas tertulias y academias, desempeña un papel importante a este respecto; no sólo porque la traducción es una de sus actividades desde un punto de vista tanto de producción como de recepción, sino también porque representa un espacio social que, por estar él mismo en vías de formación, cristaliza y refleja de forma ejemplar los procesos sociales, dinamizados, más de una vez, por un encuentro intercultural. Es incluso capaz de reflexionarlos, de proponer señas de identidad.

La provocación de la alteridad se contesta, en los ejemplos tratados, de forma muy diversa: ya sea (como vimos al final) en forma de una concepción del Estado o del monarca como traductor que asimila el saber ajeno y la novedad, que la legitima y la instrumentaliza en el sentido de su voluntad hegemónica; ya sea (en el polo opuesto) a través del proyecto de una lengua universal, brevemente evocada al ejemplo de Leibniz. Allí donde el Estado -en el caso de Vargas Ponce-, o la Iglesia -en el caso de la Tertulia historica y apologectica- contribuyen a la unificación y a la submisión de la República de las Letras y de sus actividades de traducción, allí mismo es para otros autores la propia República de las Letras la que tiene un carácter modélico para la convivencia en la nación o la comunidad de las naciones. El concepto de complementariedad de rasgos bilaterales a medir por una élite académica que se desprende del proyecto académico de Iriarte sería entonces el vínculo de unión en la cadena infinita que lleva de la teoría del poder secular o espiritual, de un Vargas Ponce o de un Ardanaz y Centellas, a la utopía de una sociedad que acoge y 
eleva - esto es, que sintetiza - la heterogeneidad bajo el signo de la traductibilidad del saber en patrones universales. Esta dialéctica de lo propio y de lo ajeno puede expresarse también - sin llegar a alternativas tan absolutas - a través del modelo de la República de las Letras que vimos traslucir en el núcleo de la tertulia, modelo de una comunidadad basada en la relación del intercambio, de la interdependencia.

No debe sorpender que el concepto idealizado de convivencia e intercambio que presentamos al ejemplo de la tertulia de la Fonda de San Sebastián no esté libre de contradicciones. Para mencionar este último ejemplo, constatemos que el conflicto en razón de la presunta primacía cultural de España sobre Italia - detectada en la enumeración de los objetivos de la traducción de Garcilaso al italiano- o de Italia sobre España se evita tan sólo por el argumento historicista de una continuación de la idea de una translatio studii y de una inversión de su dirección: en el presente, el movimiento parte de España y se dirige hacia Italia. Dicho con otras palabras: Gomez Ortega admite con dificultad una supremacía cultural italiana solamente para el pasado pues, hablando del influjo de autores italianos en Garcilaso, insiste en la originalidad estilística del poeta español. Sin embargo, no ve en su tiempo más que la necesidad de una difusión de la cultura española en Europa, aunque esta forma de nacionalismo cultural fuera mitigada por la idea de un enriquecimiento cultural mútuo, así como por metas universalistas: la fundación de una República de las Letras transnacional. También la tertulia historica y apologetica está marcada por unas aporías que demuestran, en contra de la intención de su moderador, cuán se ha alejado ya la sociedad española del consenso ideológico que siguen conjurando algunos tertulianos. La relación con la alteridad, que se manifiesta en procesos de traducción inter e intralingüística, será, nos dicen los procesos sociales que analizamos, el punto clave de la relación de España con la modernidad, un desafío permanente de su propio modo de ser como nación, y cultura, cuya alteridad o antagonismo, no será, en la historia española de las décadas siguientes, siempre superada de la forma discursiva que pudimos evocar al ejemplo de las tertulias. 